\title{
Denture-related oral mucosal lesions among farmers in a semi-arid Northeastern Region of Brazil
}

\author{
Heitor-Fontes da Silva, Paulo-Ricardo-Saquete Martins-Filho, Marta-Rabello Piva
}

Department of Oral Pathology, Dentistry School, Federal University of Sergipe, Sergipe, Brazil

Correspondence:

Universidade Federal de Sergipe,

Campus da Saúde,

Departamento de Odontologia,

Rua Cláudio Batista, s/n. Bairro Sanatório,

CEP: 49060-100. Aracaju, SE, Brazil

saqmartins@hotmail.com

Received: 29/04/2010

Accepted: 26/08/2010

da Silva HF, Martins-Filho PR, Piva MR. Denture-related oral mucosal lesions among farmers in a semi-arid Northeastern Region of Brazil. Med Oral Patol Oral Cir Bucal. 2011 Sep 1;16 (6):e740-4.

http://www.medicinaoral.com/medoralfree01/v16i6/medoralv16i6p740.pdf

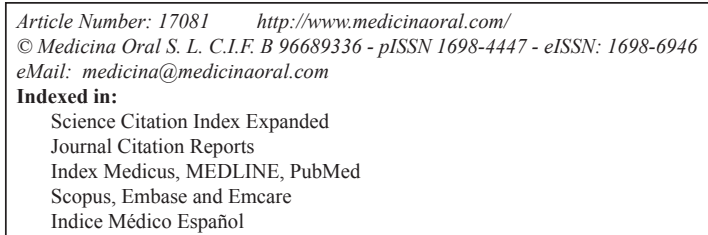

\begin{abstract}
Objectives: The purpose of this study was to evaluate the prevalence of denture-related oral mucosal lesions (DML) in São Francisco sertão microregion, in Sergipe State, Northeastern Brazil.

Study Design: Data related to gender, age, type of denture, length of denture use, hygiene care, nocturnal denture wear, symptoms, and presence of DML were obtained. Statistical analysis included the Pearson's chi-square and multivariate logistic regression.

Results: The global prevalence of DML was $50 \%$, with a significant association between the DML and female gender, age $\geq 40$ years, and length of use $\geq 5$ years. By using the interaction model of logistic regression it was observed that females over 40 years have 4.5 greater odds of developing DML compared to males of the same age group. The DML more common was the type 2 denture stomatitis, followed by type 1 denture stomatitis and inflammatory fibrous hyperplasia.

Conclusions: This study shows that the DML are more common in female over 40 years of age, suggesting that hormonal chances and age-related factors may favor the development of lesions. In addition, there is a significant association between length of denture use and prevalence of DML.
\end{abstract}

Key words: Oral mucosal lesions, removable dentures, prevalence.

\section{Introduction}

Edentulism is important as a correlate of self-esteem and quality of life in regarding to older adults (1), and it may represent the last sequel of dental caries and periodontal disease. Dental caries are the major problem of oral health in developing countries, affecting approximately $60-90 \%$ of school children and almost all adults (2).
In Brazil, tooth loss is strongly associated with living in rural areas, female gender, poor socioeconomic status, low schooling, and elderly ages. The Northeastern region concentrates the greater need to use some type of dentures (3). Despite the rehabilitative function, it is common to observe the presence of oral lesions caused by use of poorly adapted dentures or even improper instructions towards the patient, by the dentist, about the use and cleaning of dentures. 
Denture-related oral mucosal lesions (DML) have been associated with denture plaque, Candida infection, poor denture retention and mechanical trauma. Dentures may predispose patients to the onset of mucosal lesions such as denture stomatitis, angular cheilitis, inflammatory fibrous hyperplasia, and traumatic ulcer (4). To the best of our knowledge, there are few epidemiological studies in Brazil (5) that refer to denture-related mucosal lesions in rural areas.

The purpose of this study was to evaluate the prevalence of DML in São Francisco sertão microregion, in Sergipe State, Northeastern Brazil, an area with approximately 13.000 household farmers characterized by socioeconomic and health inequalities.

\section{Material and Methods}

A total of four hundred farmers were interviewed from July 2009 to April 2010. Only farmers who used some type of removable denture were included in the study accounting, therefore, a sample of 102 individuals. After being informed that consent was granted, data related to gender, age, type of denture, length of denture use, hygiene care, nocturnal denture wear, symptoms, and presence of DML were obtained. The farmers were divided into two age groups: (1) $<40$ years, and (2) $\geq 40$ years. Denture wearers were divided into complete denture wearer $(\mathrm{CDW})$ and partial denture wearer groups (PDW). The length of denture use was categorized into two groups: (1) $<5$ years of use and (2) $\geq 5$ years of use. Soft tissue examination was undertaken by using a mouth mirror and gauze compresses. Denture stomatitis diagnosis took place based on the clinical ap- pearance of the inflamed palatal mucosa, regardless of the presence of Candida albicans in cytological smears obtained from the affected area. The cases of denture stomatitis were classified into three clinical types (6): type 1, hyperaemia; type 2, generalized erythema and; type 3, papillary hyperplasia.

A data bank was generated and analyzed in OriginPro 8.0 SRO ${ }^{\circledR}$ (OriginLab Corporation, Northampton, MA, USA) software. Descriptive statistics were expressed as case numbers (n) and percentages (\%). Pearson's chisquare test was performed for discrete variables. Multivariate logistic regression analysis was performed to detect predictors of DML using factors that had significant relation in univariate analysis. A p-value less than 0.05 was regarded as significant.

The study was approved by the Research with Human Beings Ethics Committee of the Federal University of Sergipe, procotol number 0056.0.107.000-09.

\section{Results}

Of the 102 users of removable dentures, 84 were female and 18 were male. Out of whom, 52 used only PDW, 45 only CDW, and 05 both PDW and CDW. Among the users of PDW, 79\% used acrylic removable partial denture (ARPD). The average age of patients was 49 years (minimum: 18 years; maximum: 85 years).

The global prevalence of DML was $50 \%$. Women were more affected than men (56\% vs $22.2 \%)$, with a femalemale ratio of 2.5:1 $(\mathrm{p}=0.019)$. Univariate analysis revealed that the following factors were associated with DML: female gender, age $\geq 40$ years, CDW, length of use $\geq 5$ years, and mechanical cleaning (Table 1). From

Table 1. Prevalence (P) of DML according demographic and denture use variables.

\begin{tabular}{|l|c|c|c|c|c|}
\hline \multicolumn{1}{|c|}{ Variables } & Male & Female & Total & P (\%) & p-value \\
\hline $\begin{array}{l}\text { Age (years) } \\
\quad<0\end{array}$ & 07 & 23 & 30 & 30.0 & 0.018 \\
$\geq 40$ & 11 & 61 & 72 & 58.3 & \\
\hline Type of Dentures & & & & & \\
$\quad$ CDW & 06 & 51 & 57 & 64.9 & $<0.001$ \\
PDW & 14 & 48 & 62 & 30.6 & \\
\hline Length of Use (years) & & & & & \\
$\quad<5$ & 05 & 30 & 35 & 28.5 & 0.003 \\
$\quad \geq 5$ & 13 & 54 & 67 & 61.2 & \\
\hline Method of Cleaning & 17 & 68 & 85 & 70.5 & 0.013 \\
$\quad$ Mechanical & 01 & 16 & 17 & 35.3 & \\
$\quad$ Mechanical and chemical & & & & & \\
\hline Nocturnal Denture Wear & 17 & 56 & 73 & 53.4 & 0.382 \\
$\quad$ Yes & 01 & 28 & 29 & 41.4 & \\
$\quad$ No & & & & \\
\hline
\end{tabular}

p-value for the Pearson's chi-square test.

p-value less than 0.05 were considered statistically significant. 
Table 2. Multivariate logistic regression analysis.

\begin{tabular}{|l|c|c|c|c|}
\hline \multicolumn{1}{|c|}{ Variables } & $\begin{array}{c}\text { Estimated regression } \\
\text { coefficient (standard } \\
\text { deviation) }\end{array}$ & $\begin{array}{c}\text { Odds } \\
\text { ratio }\end{array}$ & CI 95\% & p-value \\
\hline Female gender & $1.99(0.72)$ & 7.38 & $1.78-30.62$ & 0.0059 \\
\hline Age $\geq \mathbf{4 0}$ years & $1.40(0.61)$ & 4.09 & $1.21-13.77$ & 0.0229 \\
\hline CDW & $0.32(0.49)$ & 1.38 & $0.52-3.67$ & 0.5133 \\
\hline Length of use $\geq \mathbf{5}$ years & $1.17(0.52)$ & 3.23 & $1.16-8.97$ & 0.0239 \\
\hline Mechanical cleaning & $0.89(0.64)$ & 2.44 & $0.69-8.59$ & 0.1636 \\
\hline
\end{tabular}

p-value less than 0.05 were considered statistically significant.

these factors, multivariate logistic regression analysis selected female gender, age $\geq 40$ years, and length of use $\geq 5$ years as the predictors to the presence of DML (Table 2). By using the interaction model of logistic regression it was observed that female over 40 years have 4.5 greater odds of developing DML if compared to male of the same age group (CI 95\%: $1.06-19.5$; $\mathrm{p}=0.04$ ). In general, for every year increase in age, the odds of DML raised by about 3\% (CI 95\%: $1.00-1.05$; $\mathrm{p}=0.04)$. In relation to length of use, it was observed that for every year increase in use, the odds of DML increased by about $05 \%$ (CI 95\%: $1.00-1.10 ; \mathrm{p}=0.02$ ).

Among the 51 farmers with DML, $92.2 \%$ presented only one type of alteration, while the remaining ones showed more than one lesion associated to the denture use, accounting a total of 56 lesions. The DML more common was the type 2 denture stomatitis (48.2\%), followed by type 1 denture stomatitis (21.4\%), inflammatory fibrous hyperplasia $(19.6 \%)$, angular cheilitis $(5.4 \%)$, traumatic ulcer (3.6\%), and type 3 denture stomatitis (1.8\%) (Fig 1). Most of the patients did not perceive the presence of DML (80.4\%).

\section{Discussion}

Although in some series it was found a higher incidence of DML in male $(4,7)$, most of the studies indicate the preference of female patients (8-10). In this study, $56 \%$ of the female presented DML during examination against approximately $22 \%$ of the male patients. According to Coelho et al. (8), the high frequency of DML among female is not well understood, but it can be explained by hormonal and age-related reasons. In perimenopausal and postmenopausal women, the atrophy of the oral mucosa and the decrease of the estrogen and progesterone can contribute to the exacerbation of the inflammatory response against chronic irritation caused by the use of removable dentures, thus increasing the incidence of DML in female patients (8). In addition, in a recent study (11), it was demonstrated that aged and denture stomatitis individuals show a lower number of salivary neutrophils than controls and present dysfunctions in the phagocytosis and killing of the C. albicans by both local and circulating neutrophils. Such alterations seem to be more pronounced in the elderly ones than in young adults since aged subjects not infected by C. albicans

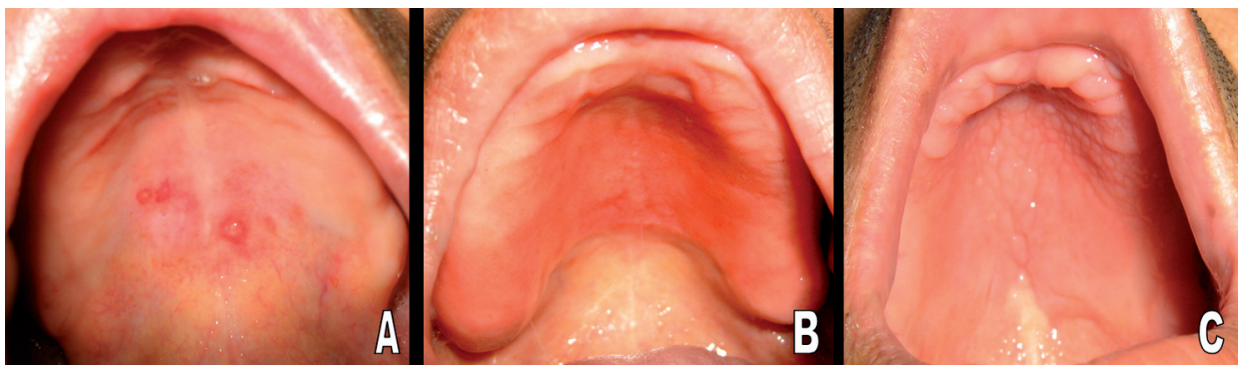

Fig. 1. Clinical aspects of denture stomatitis. A. Type 1 denture stomatitis, characterized by pinpoint hyperemia. B. Type 2 denture stomatitis, characterized by difuse erythema. C. Type 3 denture stomatitis, characterized by papillary hyperplasia with mild inflammation. 
presented impaired neutrophil function. In the present study, the results suggest that age is an important predictor for the development of DML, especially in female, which is in accordance to previous studies (8-12). Some studies have reported that there is a greater prevalence of lesions among CDW (4,8), since this type of denture covers a greater area of oral mucosa than PDW, and, therefore, a greater chance of plaque and yeast retention as well as mechanical injury is expected. However, it is clear that, when the independent variables were controlled, it was not found statistical difference in the prevalence of DML between the two types of dentures. These results indicate that PDW, especially those with acrylic base, have similar trends of developing lesions when compared to complete dentures.

This study showed that there was a greater frequency of DML as length of denture use increased, in contrast with previous studies $(5,8)$. According to Moskona and Kaplan (12), the length of denture use increases with the increasing of age, since older patients are reluctant to restore or to replace old dentures, which can cause oral lesions. In a study performed by Kanli et al. (13), only $16.7 \%$ of dentures worn by the elderly ones are properly cleaned and the older dentures tended to be dirtier than newer ones. The poor oral hygiene increases the frequency of positive cultures for Candida in the dentures (12). In addition, age is also associated with systemic diseases, nutritional deficiencies, polypharmacy, and changes in the quantity and quality of saliva. These factors, along with denture use, may facilitate changes in the oral environment and enhance the development of C. albicans (4).

Despite the logistic regression model did not indicate a higher prevalence of DML in individuals who use only the mechanical method of hygiene, some authors report that brushing is an ineffective method of denture disinfection and discuss the use of chemical agents as adjuvant, such as a new denture cleaner that contains silicone polymer and that provides a protective coating for dentures as a final step in the cleaning process (14). However, in poor communities, some of the proposed methods are inaccessible. Thus, the mechanical cleaning combined with effective and inexpensive chemical aids, such as sodium hypochlorite and coconut soap, seems to be more appropriate (15).

Although the habit of wearing dentures during sleep is important on DML development, especially denture stomatitis (16), this study did not find a statistical association between these variables. According to Emami et al. (17), nocturnal wearing of the dentures can reduce the protective effect of saliva, by cleaning the tongue, and good oxygenation of the mucosa, which are key factors in the resistance of mucosal tissue to mechanical and microbiological aggression.

Most of the denture users with DML did not perceive the presence of such disease. This way, the denture wearers should be recalled regularly for an examination of the oral cavity and the dentures to prevent the development of the DML (18).

Literature reveals a diversity of oral mucosal lesions that may arise in association with the use of removable dentures. Denture stomatitis was the most common DML observed in this study $(71.4 \%)$, but its prevalence was higher than that observed in the literature, which ranged from $18-65 \%(4,8,9,18-20)$. According to Budtz-Jorgensen (18), the denture irritation hyperplasia, which is caused by chronic injury of the tissue in contact with the denture border, is present in about $12 \%$ of denture wearers. However, the prevalence of this condition in the present study was $19.6 \%$, similar to that found in other series (8). In agreement with previous reports (8), angular cheilitis and traumatic ulcer are the less common DML and they are associated with the loss of vertical dimension and non-adapted dentures, respectively.

In conclusion, this study shows that the DML are more common in females over 40 years of age, suggesting that hormonal chances and age-related factors may favor the development of lesions. In addition to it, there is a significant association between length of denture use and prevalence of DML.

\section{References}

References with links to Crossref - DOI

1. Starr JM, Hall R. Predictors and correlates of edentulism in healthy older people. Curr Opin Clin Nutr Metab Care. 2010;13:19-23.

2. Petersen PE. Tobacco and oral health--the role of the world health organization. Oral Health Prev Dent. 2003;1:309-15.

3. Barbato PR, Muller Nagano HC, Zanchet FN, Boing AF, Peres MA. [Tooth loss and associated socioeconomic, demographic, and dental-care factors in Brazilian adults: an analysis of the Brazilian Oral Health Survey, 2002-2003]. Cad Saude Publica. 2007;23:180314.

4. Jainkittivong A, Aneksuk V, Langlais RP. Oral mucosal lesions in denture wearers. Gerodontology. 2010;27:26-32.

5. Freitas JB, Gomez RS, De Abreu MH, Ferreira E Ferreira E. Relationship between the use of full dentures and mucosal alterations among elderly Brazilians. J Oral Rehabil. 2008;35:370-4.

6. Newton AV. Denture sore mouth: a possible etiology. Br Dent J. 1962;1:357-60.

7. MacEntee MI, Glick N, Stolar E. Age, gender, dentures and oral mucosal disorders. Oral Dis. 1998;4:32-6.

8. Coelho CM, Sousa YT, Daré AM. Denture-related oral mucosal lesions in a Brazilian school of dentistry. J Oral Rehabil. 2004;31:135-9.

9. Macedo Firoozmand L, Dias Almeida J, Guimarães Cabral LA. Study of denture-induced fibrous hyperplasia cases diagnosed from 1979 to 2001. Quintessence Int. 2005;36:825-9.

10. Dorey JL, Blasberg B, MacEntee MI, Conklin RJ. Oral mucosal disorders in denture wearers. J Prosthet Dent. 1985;53:210-3.

11. Gasparoto TH, Vieira NA, Porto VC, Campanelli AP, Lara VS. Ageing exacerbates damage of systemic and salivary neutrophils from patients presenting Candida-related denture stomatitis. Immun Ageing. 2009;6:3.

12. Moskona D, Kaplan I. Oral lesions in elderly denture wearers. Clin Prev Dent. 1992;14:11-4.

13. Kanli A, Demirel F, Sezgin Y. Oral candidosis, denture cleanliness and hygiene habits in an elderly population. Aging Clin Exp Res. 2005;17:502-7. 
14. Shay K. Denture hygiene: a review and update. J Contemp Dent Pract. 2000;1:28-41.

15. Barnabé W, de Mendonça Neto T, Pimenta FC, Pegoraro LF, Scolaro JM. Efficacy of sodium hypochlorite and coconut soap used as disinfecting agents in the reduction of denture stomatitis, Streptococcus mutans and Candida albicans. J Oral Rehabil. 2004;31:453-9. 16. Compagnoni MA, Souza RF, Marra J, Pero AC, Barbosa DB. Relationship between Candida and nocturnal denture wear: quantitative study. J Oral Rehabil. 2007;34:600-5.

17. Emami E, Séguin J, Rompré PH, de Koninck L, de Grandmont P, Barbeau J. The relationship of myceliated colonies of Candida albicans with denture stomatitis: an in vivo/in vitro study. Int J Prosthodont. 2007;20:514-20.

18. Budtz-Jørgensen E. Oral mucosal lesions associated with the wearing of removable dentures. J Oral Pathol. 1981;10:65-80.

19. Mujica V, Rivera H, Carrero M. Prevalence of oral soft tissue lesions in an elderly venezuelan population. Med Oral Patol Oral Cir Bucal. 2008;13:E270-4.

20. Cebeci AR, Gülşahi A, Kamburoglu K, Orhan BK, Oztaş B. Prevalence and distribution of oral mucosal lesions in an adult Turkish population. Med Oral Patol Oral Cir Bucal. 2009;14:E272-7. 